\title{
The Mobi-C cervical disc for one-level and two-level cervical disc replacement: a review of the literature
}

This article was published in the following Dove Press journal:

Medical Devices: Evidence and Research

26 November 2014

Number of times this article has been viewed

\author{
Matthew D Alvin ${ }^{1,2}$ \\ Thomas E Mroz ${ }^{1,3,4}$ \\ 'Cleveland Clinic Center for Spine \\ Health, Cleveland Clinic, Cleveland, \\ $\mathrm{OH}$, USA; ${ }^{2}$ Case Western Reserve \\ University School of Medicine, \\ Cleveland, OH, USA; ${ }^{3}$ Cleveland \\ Clinic Lerner College of Medicine, \\ Cleveland, OH, USA; ${ }^{4}$ Department \\ of Neurological Surgery, Cleveland \\ Clinic, Cleveland, OH, USA
}

Background: Cervical disc arthroplasty (CDA) is a novel motion-preserving procedure that is an alternative to fusion. The Mobi-C disc prosthesis, one of many Food and Drug Administration (FDA)-approved devices for CDA, is the only FDA-approved prosthesis for two-level CDA. Hence, it may allow for improved outcomes compared with multilevel fusion procedures.

Purpose: To critically assess the available literature on CDA with the Mobi-C prosthesis, with a focus on two-level CDA.

Methods: All clinical articles involving the Mobi-C disc prosthesis for CDA through September 1, 2014 were identified on Medline. Any paper that presented Mobi-C CDA clinical results was included. Study design, sample size, length of follow-up, use of statistical analysis, quality of life outcome scores, conflict of interest, and complications were recorded.

Results: Fifteen studies were included that investigated Mobi-C CDA, only one of which was a level Ib randomized control trial. All studies included showed non-inferiority of one-level Mobi-C CDA to one-level anterior cervical discectomy and fusion (ACDF). Only one study analyzed outcomes of one-level versus two-level Mobi-C CDA, and only one study analyzed two-level Mobi-C CDA versus two-level ACDF. In comparison with other cervical disc prostheses, the Mobi-C prosthesis is associated with higher rates of heterotopic ossification (HO). Studies with conflicts of interest reported lower rates of HO. Adjacent segment degeneration or disease, along with other complications, were not assessed in most studies.

Conclusion: One-level Mobi-C CDA is non-inferior, but not superior, to one-level ACDF for patients with cervical degenerative disc disease. The Mobi-C CDA procedure is associated with high rates of HO. Two-level Mobi-C CDA may be superior to two-level ACDF. However, insufficient evidence exists, thereby mandating a need for unbiased, well-designed prospective studies with well-defined outcomes in the future.

Keywords: Mobi-C, cervical disc arthroplasty, total disc replacement, ACDF, quality of life, outcomes, effectiveness, cervical spine

\section{Introduction}

Cervical disc arthroplasty (CDA) has been deemed an equivalent and, in some studies, superior alternative to anterior cervical discectomy and fusion (ACDF) for patients with cervical radiculopathy or myelopathy. ${ }^{1-6}$ It has been marketed as, unlike ACDF, able to retain mobility at the operated spinal levels while inducing both pain relief and improved function. Many investigational device exemption trials on different types of these devices (eg, Bryan [Medtronic Sofamor Danek, Memphis, TN, USA], ProDisc [Synthes Spine, Paoli, PA, USA], Prestige [Medtronic Sofamor Danek]) have been conducted and consistently show that CDA is a safe alternative to ACDF, with equivalent or greater effectiveness. ${ }^{1-6}$ However, these trials have focused on one-level CDA. 
The Mobi-C cervical disc prosthesis (LDR Spine USA, Inc., Austin, TX, USA) is Food and Drug Administration (FDA)-approved for one-level (8-7-2013, P110002) and twolevel (adjacent) use (8-23-2013, P110009). It contains two cobalt-chrome alloy shells with an intervening polyethylene insert (Figure 1). It has lateral self-retaining teeth, designed for optimal stability and anchoring. The insert's mobility may reduce constraints on the posterior facet joints, though this has not been proven. Currently, the Mobi-C disc has FDA approval as the first and only artificial disc for both singlelevel and two-level CDA. ${ }^{1}$ The purpose of this study was to review the current literature on the Mobi-C disc, with a focus on two-level cervical arthroplasty.

\section{Methods}

A literature search was performed using the Medline database via the PubMed search engine with the following search terms: "Mobi-C", "cervical disc arthroplasty", "cervical disc replacement", and "disc replacement". Any studies that presented clinical results associated with the Mobi-C cervical disc prosthesis were included. Biomechanical studies, radiographic studies, and animal studies were excluded, as were articles dealing with nucleus replacement. No limitations prevented us from including studies on the Mobi-C disc. All articles were reviewed and classified according to level of evidence (LOE) independently by two of the authors. The criteria put forth by Sackett et $\mathrm{al}^{7}$ were used to analyze the data (Table 1) and stratify according to LOE. For the purposes of this study, only levels Ib, IIb, IIIb, and IV were relevant. The reasons for low LOE included lack of adequate follow-up $(<85 \%$ of original sample size), incomplete reporting of important outcome measures or percentage of subjects available at follow-up, complete absence or incomplete reporting of statistical analysis of results, and/or inadequate sample size, which was defined in this study as $\mathrm{n}<50$ patients undergoing CDA.

All randomized controlled, retrospective, and prospective studies were presented for completeness. All articles were

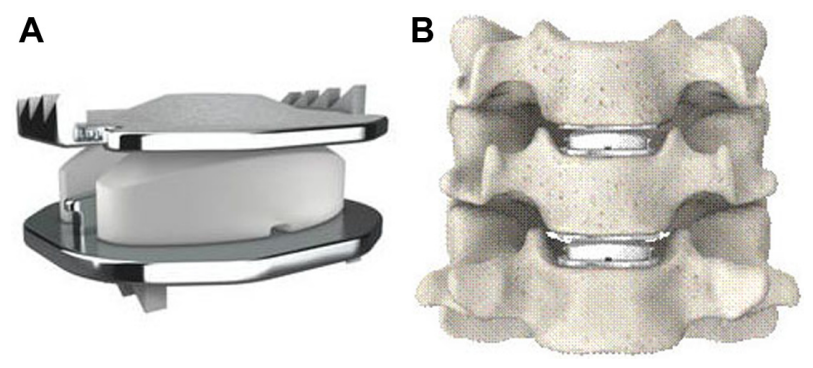

Figure I Mobi-C Disc Prosthesis (A) and representation of two-level use (B). Note:Datafromhttp://www.fda.gov/MedicalDevices/ProductsandMedicalProcedures/ DeviceApprovalsandClearances/Recently-ApprovedDevices/ucm367809.htm. ${ }^{38}$
Table I Levels of Evidence

\begin{tabular}{ll}
\hline Level of evidence & Study type \\
\hline la & Systematic review of RCTs (with homogeneity) \\
Ib & Individual RCT with narrow confidence \\
& interval (blind or independent assessment \\
& of important outcome measures, follow-up \\
& rate equal or greater than $85 \%$ at 24 months, \\
& adequate sample size, intent-to-treat analysis \\
& and concealment) \\
& All or none \\
Ic & Systematic review of cohort studies \\
Ila & Individual cohort study, low quality RCT, case- \\
Ilb & control study, good quality retrospective \\
& Outcomes research \\
Ilc & Systematic review of case-control studies \\
IIla & Individual case-control study \\
IIIb & Case series, poor-quality cohort and case- \\
IV & control studies \\
V & Expert opinion without explicit critical \\
& appraisal \\
\hline Abbration
\end{tabular}

Abbreviation: RCT, randomized control trial.

Note: Data from Sackett et al. ${ }^{7}$

then evaluated with regard to conflict of interest (COI) by review of their respective disclosure sections. Any remunerative or non-financial activity with the potential of creating bias in the author or author(s) of a published manuscript was considered a COI per the guidelines published online by the North American Spine Society (NASS) ${ }^{8}$ All included journals had a minimum of certain disclosure requirements, and those were used to determine whether there was any bias among the authors. Complications and/or adverse outcomes assessed included heterotopic ossification (HO), adjacent segment degeneration (ASDG), adjacent segment disease, or other, such as dysphagia or reoperation. Adjacent segment disease, which is defined by symptom presentation clinically, was considered a distinct entity from ASDG, which is defined by radiographic presentation. ACDF was performed with allograft and plating. Range of motion (ROM) was reported as "same" or "improved" based on the patient's baseline preoperative ROM due to the cervical disease and postoperative improvement, if it occurred.

\section{Results}

Fifteen studies that involved Mobi-C CDA were included: one randomized control trial, five prospective studies, and nine retrospective studies (Tables 2 and 3). These studies encompassed a total of 1,319 patients undergoing Mobi-C CDA. Only two studies ${ }^{9,10}$ were controlled with an ACDF cohort, and five studies reported a COI., ${ }^{911-14}$ Only two studies specifically focused on two-level CDA, while five other studies included at least one patient who had two-level CDA. 
Table 2 Summary of included studies

\begin{tabular}{|c|c|c|c|c|c|c|c|c|c|c|c|}
\hline Study & Year & Design & Levels & n (\# two-level) & $\begin{array}{l}\text { Mean FU, } \\
\text { months (\%) }\end{array}$ & NDI & $\begin{array}{l}\text { VAS } \\
\text { neck }\end{array}$ & $\begin{array}{l}\text { VAS } \\
\text { arm }\end{array}$ & $\begin{array}{l}\text { SF-36 } \\
\text { MCS }\end{array}$ & $\begin{array}{l}\text { SF-36 } \\
\text { PCS }\end{array}$ & ROM \\
\hline Oh et $\mathrm{al}^{23}$ & 2014 & $\mathrm{R}$ & I & $60 \mathrm{CDA}$ & 18 & - & Imp & $\operatorname{Imp}$ & - & - & $\operatorname{Imp}$ \\
\hline Davis et al ${ }^{9}$ & 2013 & RCT & 1 and 2 & $\begin{array}{l}225 \text { CDA (225) } \\
105 \text { ACDF }\end{array}$ & $24(100 \%)$ & $\operatorname{Imp}$ & Same & Same & - & - & Same \\
\hline Park et $\mathrm{al}^{16}$ & 2013 & $\mathrm{R}$ & 1 and 2 & 75 CDA (10) & 24 & Imp & Imp & Imp & - & - & - \\
\hline Park et $\mathrm{al}^{22}$ & 2013 & $\mathrm{R}$ & I & 14 CDA & 36 & & & & & & \\
\hline Yi et al ${ }^{2}$ & 2013 & $\mathrm{R}$ & I & $170 \mathrm{CDA}$ & 20 & - & - & - & - & - & - \\
\hline Guérin et al" & 2012 & PC & 1 and 2 & $71 \mathrm{CDA}(12)$ & 21 & - & Imp & Imp & Imp & $\operatorname{Imp}$ & - \\
\hline Guérin et al ${ }^{17}$ & 2012 & PC & 1 & $40 \mathrm{CDA}$ & 24 & Imp & Imp & Imp & Imp & $\operatorname{Imp}$ & Same \\
\hline Lee et $\mathrm{al}^{19}$ & 2012 & PC & I & $28 \mathrm{CDA}$ & 24 (78.5\%) & $\operatorname{Imp}$ & Imp & Imp & - & - & - \\
\hline Huppert et $\mathrm{al}^{12}$ & 2011 & PC & 1 and 2 & $23 \mid \mathrm{CDA}(5 \mathrm{I})$ & $24(100 \%)$ & $\operatorname{Imp}$ & Imp & Imp & - & - & Same \\
\hline Bao et $\mathrm{al}^{20}$ & 2011 & $\mathrm{R}$ & 2 & $20 \mathrm{CDA}$ & $16(100 \%)$ & Imp & Imp* & $\operatorname{Imp} *$ & - & - & Same \\
\hline Jin et $\mathrm{al}^{21}$ & 2011 & $\mathrm{R}$ & I & $67 \mathrm{CDA}$ & $12(76 \%)$ & - & Imp & Imp & - & Imp & Same \\
\hline Yi et al $\left.\right|^{14}$ & 2010 & $R$ & 1 and 2 & 6I CDA (I) & $14(100 \%)$ & - & - & - & - & - & - \\
\hline Beaurain et al ${ }^{18}$ & 2009 & PC & 1 and 2 & $76 \mathrm{CDA}(9)$ & $24(100 \%)$ & Imp & Imp & Imp & Imp & $\operatorname{Imp}$ & Same \\
\hline Park et al ${ }^{10}$ & 2008 & $\mathrm{R}$ & 1 & $\begin{array}{l}32 \mathrm{CDA} \\
21 \mathrm{ACDF}\end{array}$ & 20 & Imp & Imp & Imp & - & - & - \\
\hline Kim et al ${ }^{15}$ & 2007 & $\mathrm{R}$ & 1 and 2 & $23 \mathrm{CDA}(\mathrm{I})$ & 6 & - & $\operatorname{Imp}$ & Imp & - & - & - \\
\hline
\end{tabular}

Note: *Differentiation between VAS arm and neck scores not provided.

Abbreviations: ACDF, anterior cervical discectomy and fusion; CDA, cervical disc arthroplasty; FU, clinical follow-up; Imp, improved; MCS, mental component summary; NDI, neck disability index; PC, prospective cohort; PCS, physical component summary; R, retrospective; RCT, randomized control trial; ROM, range of motion; SF-36, ShortForm 36; VAS, visual analog scale.

\section{One-level CDA}

The first study analyzing the Mobi-C disc was published in 2007 by Kim et al. ${ }^{15}$ This retrospective study ( $\left.\mathrm{n}=23\right)$ on one-level CDA showed improved quality of life (QOL) and functional outcomes, as well as presented a simple and reproducible surgical technique. Results showed significantly

Table $3 \mathrm{COI}$ and complications

\begin{tabular}{|c|c|c|c|c|c|}
\hline Author & Year & LOE & COI & HO & ASDG \\
\hline Oh et $\mathrm{al}^{23}$ & 2014 & Illb & None & - & - \\
\hline \multirow[t]{2}{*}{ Davis et al ${ }^{9}$} & 2013 & $\mathrm{lb}$ & Funded & $4.9 \%$ & $16 \%$ CDA \\
\hline & & & by LDR ${ }^{a}$ & & $51 \%$ ACDF \\
\hline Park et $\mathrm{al}^{16}$ & 2013 & Ilb & NDS & $94.1 \%$ & None \\
\hline Park et $\mathrm{al}^{22}$ & 2013 & IV & None & - & $14.2 \%$ CDA \\
\hline Yi et al ${ }^{2}$ & 2013 & $\mathrm{llb}$ & $\begin{array}{l}\text { Institutional } \\
\text { funding }\end{array}$ & $52.5 \%$ & - \\
\hline Guérin et al" & 2012 & Illb & $\begin{array}{l}\text { Corporate } \\
\text { funding }\end{array}$ & $27.7 \%$ & None \\
\hline Guérin et al ${ }^{17}$ & 2012 & IV & None & - & - \\
\hline Lee et $\mathrm{al}^{19}$ & 2012 & IV & None & $77.3 \%$ & None \\
\hline Huppert et al ${ }^{12}$ & 2011 & Ilb & $\begin{array}{l}\text { Institutional } \\
\text { funding }\end{array}$ & $62 \%$ & None \\
\hline Bao et $\mathrm{al}^{20}$ & 2011 & IV & NDS & - & - \\
\hline Jin et $a^{21}$ & 2011 & IV & NDS & $47 \%$ & None \\
\hline Yi et al ${ }^{14}$ & 2010 & IV & $\begin{array}{l}\text { Institutional } \\
\text { funding }\end{array}$ & $52.5 \%$ & - \\
\hline Beaurain et $\mathrm{al}^{18}$ & 2009 & llb & NDS & $67 \%$ & $9.1 \% \mathrm{CDA}$ \\
\hline Park et al ${ }^{10}$ & 2008 & IV & NDS & None & None \\
\hline Kim et $\mathrm{al}^{15}$ & 2007 & IV & NDS & None & None \\
\hline
\end{tabular}

Note: aLDR Spine USA, Inc., Austin, TX, USA.

Abbreviations: ACDF, anterior cervical discectomy and fusion; ASDG, adjacent segment degeneration; CDA, cervical disc arthroplasty; COI, conflict of interest; $\mathrm{HO}$, heterotopic ossification; LOE, level of evidence; NDS, no disclosure section. improved $(P<0.01)$ visual analog scale $($ VAS $)$ scores (axial pain and radiculopathy) at 6 months follow-up. Park et a ${ }^{10}$ retrospectively assessed outcomes in 53 patients ( 21 one-level CDA and $32 \mathrm{ACDF}$ ) with cervical disc herniations. Both mean hospital stay (5.6 vs 6.3 days, respectively) and time to return to work after surgery (1 vs 3 weeks, respectively) were significantly $(P<0.05)$ shorter in the CDA cohort. With a mean follow-up of 12 months, both cohorts saw improved neck disability index (NDI) and VAS scores, but were not statistically different from one another. No complications were noted for the CDA cohort, whereas the ACDF cohort had five instances of cage subsidence. The same authors then looked at the incidence of and risk factors for $\mathrm{HO}$ in 75 patients who underwent CDA. ${ }^{16}$ At 2 years postoperative, the $\mathrm{HO}$ rate was $94.1 \%$, and both alignment and segmental motion decreased compared with preoperatively, which the authors attributed to the high $\mathrm{HO}$ rate. Ten patients underwent two-level CDA, but the authors did not differentiate between one- and two-level cohorts. VAS neck/arm and NDI scores both improved significantly. The only risk factor for developing $\mathrm{HO}$ was surgical technique. Two surgeons independently performed all operations in the study. To trim endplates, surgeon A used a fluted ball-type burr, while surgeon B used a diamond-type burr. Subsequently, surgeon A had significantly more patients develop HO.

Guérin et al ${ }^{17}$ conducted a prospective study ( $\mathrm{n}=40$; mean 2-year follow-up) to analyze sagittal balance after one-level CDA. Patients saw statistically significantly 
improved NDI, VAS, and Short-Form 36 (SF-36) scores, as well as maintained ROM, cervical lordosis, and sagittal alignment of the cervical spine, at 2 years postoperative. In a prospective analysis ( $\mathrm{n}=71$; mean follow-up 21 months $),{ }^{11}$ the same authors identified the CDA HO rate as $27.7 \%$. Twelve patients underwent two-level replacement. The authors found no significant differences in QOL outcomes (VAS neck/arm and SF-36) between one-level and two-level patients. No difference in QOL outcomes existed for patients with $\mathrm{HO}$ and those without. However, the authors found significantly lower HO rates in the two-level cohort $(54.9 \%$ vs $66.7 \%, P<0.05)$. Beaurain et $\mathrm{al}^{18}$ reported on the intermediate results ( $\mathrm{n}=76$; mean 2-year follow-up) of an ongoing multicenter prospective study of CDA with the Mobi-C prosthesis. Their goal was to establish safety and efficacy of the procedure without comparison to ACDF. NDI, VAS arm/neck, and SF-36 scores improved significantly. ROM was maintained. HO rate was $67 \%$, and ASDG rate was 9.1\%. After 2 years, $91 \%$ of patients that underwent CDA reported they would do so again. Two-level operations were performed in nine $(11.8 \%)$ patients, but one- and two-level cohorts were not compared.

Lee et al ${ }^{19}$ retrospectively assessed 28 patients who underwent $\mathrm{CDA}$ with the Mobi-C device to determine the HO rate. At 2 years postoperative, $64.3 \%$ of patients $(18 / 28)$ had developed HO. Cervical ROM was preserved in grades I or II HO $(50 \% ; 14 / 28$ patients $)$, but was restricted in grades III or IV $(50 \% ; 14 / 28$ patients $)$. However, HO did not correlate with worse QOL outcomes (NDI and VAS scores). Both NDI and VAS scores had significantly improved in all patients at 2 years postoperative. Bao et $\mathrm{al}^{20}$ prospectively (16.5-month average follow-up) analyzed 20 patients who received Mobi-C CDA (five cases of two-level CDA) and found significantly $(P<0.01)$ improved NDI and VAS scores compared with the preoperative state. Jin et $\mathrm{al}^{21}$ retrospectively analyzed patients $(n=67)$ with cervical radiculopathy who underwent Mobi-C CDA. The cohort had a 1-year follow-up and showed significantly improved SF-36 and VAS QOL scores, as well as preserved ROM. Park et $\mathrm{al}^{22}$ compared the Mobi-C, Bryan, Porous Coated Motion (PCM), and Prestige LP discs. The authors found that patients who received the Mobi-C or Bryan discs showed increased ROM at the index level but had a higher incidence of ASDG (14.2\% and 25\%, respectively) than patients who received either the Prestige LP or PCM discs ( $9 \%$ and $7.6 \%$, respectively). Overall, all discs preserved ROM and cervical lordosis. Most recently, Oh et $\mathrm{al}^{23}$ conducted a retrospective 18 -month follow-up study $(n=60)$ to evaluate clinical and radiologic outcomes after arthroplasty with the
Mobi-C prosthesis. All patients had degenerative disc disease (DDD) and were split into two cohorts: mild and severe, classified via a radiologic scale known as Pfirrmann grade. The authors found no difference in VAS, Oswestry Disability Index, or ROM between cohorts, but did show significant QOL outcome improvement at all follow-up points for both cohorts. Two studies by Yi et al ${ }^{13,14}$ focused on identifying the $\mathrm{HO}$ rate for various types of cervical prostheses, including the Mobi-C disc, which had an $\mathrm{HO}$ rate of $52.5 \%$.

\section{Two-level CDA}

Huppert et al $^{12}$ analyzed the safety and efficacy of one-level vs two-level Mobi-C CDA for patients with cervical DDD ( $\mathrm{n}=175$ one-level, $\mathrm{n}=51$ two-level). NDI and VAS arm/neck scores, as well as mobility, improved significantly for both cohorts, but with no significant difference between cohorts. In the two-level cohort, analgesic use was significantly higher while the HO rate was significantly lower than in the one-level cohort.

In a prospective, randomized, United States FDA investigational device exemption trial, Davis et $\mathrm{al}^{9}$ compared Mobi-C CDA vs ACDF for two-level contiguous cervical DDD over a follow-up of 2 years (97\% follow-up). Of the 330 patients enrolled, 225 (68\%) underwent two-level CDA, and 105 (32\%) underwent ACDF (2:1 ratio). Both cohorts experienced statistically significant improvements in NDI and VAS arm/neck scores compared with preoperative values. In addition, the CDA cohort experienced significantly greater improvement in NDI score than the ACDF cohort $(P<0.05)$. ROM was maintained at both treated segments. The reoperation rate was significantly higher in the ACDF cohort $(11.4 \%)$ compared with the CDA cohort $(3.1 \%)$. Lower adverse events were reported for the CDA cohort. Overall study success rates, defined as a combination of NDI improvement, no adverse events or reoperations, and radiographic success, were statistically superior for the CDA cohort compared with the ACDF cohort (69.7\% vs $37.4 \% ; P<0.01)$. The authors provided only the Grade IV $\mathrm{HO}$ rate for CDA at 2 years (4.9\%, eleven patients). ASDG rates were significantly lower for the CDA cohort vs ACDF cohort (16\% vs 51\%, $P<0.03)$.

\section{Discussion}

The primary goal of CDA is to preserve or improve the ROM of the spine as well as prevent ASDG. In the United States, several different arthroplasty devices have undergone extensive investigational studies and subsequently been FDAapproved for use nationwide. Many different prosthetic 
devices for CDA have been created, such as the ProDisc-C (Synthes Spine), Bryan (Medtronic Sofamor Danek), and Prestige (Medtronic Sofamor Danek). Each device differs by its fixed or mobile core, unconstrained or constrained nature, and location and type of device cores. ${ }^{22}$ These differences impact cervical alignment and motion. Many different literature reviews and meta-analyses have been conducted that provide support for one-level CDA as a safe and effective alternative to one-level ACDF and, in many studies, superiority of the former over the latter. ${ }^{1-6}$ Aghayev et $\mathrm{al}^{24}$ showed that CDA also provides long-term (5-year) stability, pain alleviation, and QOL improvement. However, given that many patients with DDD require multilevel fusion, it is important to compare multilevel CDA to multilevel ACDF.

This multilevel comparison has been performed sparsely in the literature for CDA in general. In 2003, Goffin et $\mathrm{al}^{25}$ reported clinical results at 1 year postoperative for two-level Bryan CDA ( $n=43)$ as clinically successful (ie, based on modified Odom's criteria) in over $96 \%$ of cases at 1 -year follow-up. Cheng et $\mathrm{al}^{26}$ conducted a randomized control trial of ACDF vs CDA with the Bryan prosthesis $(n=65)$ for two-level cervical DDD. At 2 years postoperative, both cohorts saw significantly improved NDI and VAS scores, with the former being significantly more improved $(P=0.02)$ in the CDA cohort. Pimenta et $\mathrm{al}^{27}$ conducted a prospective analysis $(n=140)$ of one- vs two-level CDA with the PCM prosthesis ( $\mathrm{n}=69$ two-level, $\mathrm{n}=71$ one-level; mean follow-up of 26 months). NDI scores were significantly more improved in the two-level cohort $(P=0.02)$. VAS score improvement and complication rates were similar between the cohorts. As identified in the present study, Huppert et $\mathrm{al}^{12}$ found no significant differences among QOL outcomes between one- and two-level cohorts. In 2012, Kepler et $\mathrm{al}^{28}$ conducted a literature review showing that there is insufficient evidence on multilevel CDA vs ACDF, with only the Huppert et $\mathrm{al}^{12}$ study looking at the Mobi-C prosthesis, but not in comparison to ACDF. Since that article, only Davis et $\mathrm{al}^{9}$ have conducted a study comparing two-level Mobi-C CDA vs two-level $\mathrm{ACDF}$ and, as discussed above, showed significant greater "success" rates for CDA.

The following conclusions can be drawn from the present study review: 1) one-level Mobi-C CDA is non-inferior, but not superior, to one-level ACDF for patients with cervical DDD; 2) the Mobi-C CDA procedure is associated with high rates of $\mathrm{HO}$; and 3) two-level Mobi-C CDA may be superior to two-level ACDF, but substantial evidence is lacking beyond the findings of one study with a significant
COI. HO, defined as formation of bone outside the skeletal system with unknown etiology, is a well-known complication of CDA and is commonly identified on cervical lateral radiographs. In 2012, Chen et $\mathrm{al}^{29}$ conducted a meta-analysis of $\mathrm{HO}$ after CDA and found a pooled prevalence of $44.6 \%$ 1 year after CDA. In the first study to publish the $\mathrm{HO}$ rate for the Mobi-C disc, Yi et al ${ }^{14}$ retrospectively analyzed the occurrence of $\mathrm{HO}$ in patients $(\mathrm{n}=170$; Bryan -81 , Mobi-C -61 , ProDisc-C - 28) who underwent CDA and stratified the overall $\mathrm{HO}$ rate $(40.6 \%)$ by disc type: Bryan disc $(21 \%)$, Mobi-C disc (52.5\%), and ProDisc-C disc (71.4\%). In a follow-up study with the same patient sample, Yi et $\mathrm{al}^{13}$ sought to identify predisposing factors for $\mathrm{HO}$ after CDA. The authors found that only male sex (odds ratio [OR] of 2.117) and device type (OR of 5.262 and 7.449 for Mobi-C and ProDisc-C, respectively) were associated with a higher likelihood for development of HO. In a recently published review of CDA, ${ }^{1}$ studies on Prestige discs reported the lowest HO rates ( $\mathrm{n}=7$ studies; $0 \%-3.2 \%$ ), followed by Bryan discs ( $\mathrm{n}=40$ studies; 0\%-17.8\%), PCM discs ( $\mathrm{n}=4$ studies; 0\%-38\%), ProDisc-C discs ( $\mathrm{n}=11$ studies; $2.9 \%-88 \%$ ), and finally Mobi-C discs ( $\mathrm{n}=7$ studies; 62\%-94.1\%). Differences in design, biomechanical characteristics, endplate articulation component, and surgical procedure could contribute to variations in $\mathrm{HO}$ by disc type. Besides differences in $\mathrm{HO}$ by disc type, differences may exist relative to one- or two-level disease. Wu et $\mathrm{al}^{30}$ analyzed 70 patients (42 onelevel, 28 two-level) who underwent CDA with the Bryan disc and found a higher $\mathrm{HO}$ rate in two-level patients $(75 \%$ vs $40.5 \% ; P<0.01)$. Finally, the number of fusions after CDA complicated by severe $\mathrm{HO}$ was not quantified and would have impacted the success rate greatly.

While Davis et $\mathrm{al}^{9}$ did show superiority of two-level Mobi-C vs two-level ACDF, any study receiving funding by the corporation (LDR Spine USA, Inc.) who manufactured the disc being studied raises questions about the validity of those results due to potential bias. Specifically, the reported $\mathrm{HO}$ rate of $4.9 \%$ by the study authors differs significantly from that reported by every other study included (range $27.7 \%-94.1 \%$ ). In a study evaluating COI in the scientific literature, Bhandari et $\mathrm{al}^{31}$ examined 332 randomized trials in 13 leading surgical and medical journals in order to determine whether an association existed between industry financial involvement and trial outcome(s). Industry funding was associated with a statistically significant supportive result (OR 1.9, 95\% confidence interval [CI] 1.3-3.5). After adjustment for study quality and sample size, the association remained significant (adjusted OR 1.8, 95\% CI 1.1-3.0). 
Given the rapidly growing market of CDA prostheses, estimated to be in the hundreds of millions of dollars, it is critical that potential biases are nullified and controlled in future studies on this topic. ${ }^{1}$

Finally, a comparison of surgical techniques for the same indication is not complete without a discussion of cost-effectiveness. Using Medicare national reimbursement amounts, CPT (current procedural terminology) codes, and DRG (diagnosis-related group) codes, procedural costs for one-level CDA and ACDF are US\$1,685 and US\$1,742, respectively, with additional levels adding on an extra US\$400 per level. Hospital costs for CDA and ACDF are US\$10,483 and US\$10,842, respectively. ${ }^{32-34}$ Thus, overall the patient is not saving much money upfront in having CDA over ACDF. Nandyala et $\mathrm{al}^{35}$ analyzed data from the Nationwide Inpatient Sample (2002-2009) and found that, indeed, no significant differences existed in overall hospital costs between ACDF and CDA patients. However, the key difference arises with QOL gained by the patient from the surgical procedures. Given near equal cost, if CDA produces greater gains in $\mathrm{QOL}$ for patients than ACDF, then it would be more cost effective than ACDF. In a decision-tree analysis, Qureshi et $\mathrm{al}^{36}$ showed that CDA had the potential to be more cost effective than ACDF after 14 years follow-up. In a follow-up study involving the ProDisc prosthesis, the same authors identified no significant difference in QOL improvement scores between CDA and ACDF at 24 months follow-up. ${ }^{37}$ In the present study, only Park et $\mathrm{al}^{10}$ and Davis et $\mathrm{al}^{9}$ compared Mobi-C CDA with ACDF. The former (no COI) found no differences in QOL outcomes at 12 months follow-up, while the latter (funded by LDR Spine USA, Inc.) found significant $(P<0.05)$ improvement in NDI scores in the Mobi-C CDA cohort at 24 months follow-up. Thus, more studies are needed specifically comparing Mobi-C CDA with ACDF to be able to make conclusions on cost effectiveness.

The primary limitation of this review is how differences among study classification systems for HO or ASDG may impact the results presented here. Given a lack of exact definitions by each study, the complication rates assessed may never be completely comparable. This is a limitation of most systematic reviews of both prospective and retrospective studies.

\section{Conclusion}

One-level Mobi-C CDA is non-inferior, but not superior, to one-level ACDF for patients with cervical DDD. The Mobi-C CDA procedure is associated with high rates of HO. Two-level Mobi-C CDA may be superior to twolevel ACDF. However, insufficient evidence exists, thereby mandating a need for unbiased, well-designed prospective studies with well-defined outcomes in the future.

\section{Disclosure}

The authors report no conflicts of interest in this work.

\section{References}

1. Alvin MD, Abbott EE, Lubelski D, et al. Cervical arthroplasty: a critical review of the literature. Spine J. 2014;14(9):2231-2245.

2. Yin S, Yu X, Zhou S, Yin Z, Qiu Y. Is cervical disc arthroplasty superior to fusion for treatment of symptomatic cervical disc disease? A meta-analysis. Clin Orthop Relat Res. 2013;471:1904-1919.

3. Xing D, Ma X, Ma J, Wang J, Ma T, Chen Y. A meta-analysis of cervical arthroplasty compared to anterior cervical discectomy and fusion for single-level cervical disc disease. J Clin Neurosci. 2013;20:970-978.

4. Oh $\mathrm{CH}$, Yoon SH. Past, present, and future of cervical arthroplasty. Keio J Med. 2013;62(2):47-52.

5. Yu Gao MM, Liu M, Li T, Huang F, Tang T, Xiang Z. A meta-analysis comparing the results of cervical disc arthroplasty with anterior cervical discectomy and fusion (ACDF) for the treatment of symptomatic cervical disc disease. J Bone Joint Surg Am. 2013;95:555-561.

6. Boselie TFM, Willems PC, van Mameren H, de Bie RA, Benzel EC, van Santbrink H. Arthroplasty versus fusion in single-level cervical degenerative disc disease: a Cochrane review. Spine. 2013;38:E1096-E1107.

7. Sackett DL, Strauss SE, Richardson WS, et al. Evidence-Based Medicine: How to Practice and Teach EBM. Philadelphia, PA: Churchill-Livingstone; 2000.

8. NASS Disclosure Policy. Revised March 2012. North American Spine Society. Available from: http://www.spine.org/Pages/PracticePolicy/EthicsProfConduct/NASSDisclosurePolicy. Accessed August 1, 2014.

9. Davis RJ, Kim KD, Hisey MS, et al. Cervical total disc replacement with the Mobi-C cervical artificial disc compared with anterior discectomy and fusion for treatment of 2-level symptomatic degenerative disc disease: a prospective, randomized, controlled multicenter clinical trial: clinical article. J Neurosurg Spine. 2013;19:532-545.

10. Park JH, Roh KH, Cho JY, Ra YS, Rhim SC, Noh SW. Comparative analysis of cervical arthroplasty using Mobi- $\mathrm{C}^{\circledR}$ and anterior cervical discectomy and fusion using the Solis ${ }^{\mathbb{}}$-cage. $J$ Korean Neurosurg Soc. 2008;44:217-221.

11. Guérin P, Obeid I, Bourghli A, et al. Heterotopic ossification after cervical disc replacement: clinical significance and radiographic analysis. A prospective study. Acta Orthop Belg. 2012;78:80-86.

12. Huppert J, Beaurain J, Steib JP, et al. Comparison between single- and multi-level patients: clinical and radiological outcomes 2 years after cervical disc replacement. Eur Spine J. 2011;20:1417-1426.

13. Yi S, Shin DA, Kim KN. The predisposing factors for the heterotopic ossification after cervical artificial disc replacement. Spine J. 2013;13:1048-1054.

14. Yi S, Kim KN, Yang MS. Difference in occurrence of heterotopic ossification according to prosthesis type in the cervical artificial disc replacement. Spine (Phila Pa 1976). 2010;35:1556-1561.

15. Kim SH, Shin HC, Shin DA, Kim KN, Yoon do H. Early clinical experience with the mobi-C disc prosthesis. Yonsei Med J. 2007;48:457-464.

16. Park JH, Rhim SC, Roh SW. Mid-term follow-up of clinical and radiologic outcomes in cervical total disk replacement (Mobi-C): incidence of heterotopic ossification and risk factors. J Spinal Disord Tech. 2013;26:141-145.

17. Guérin P, Obeid I, Gille O, et al. Sagittal alignment after single cervical disc arthroplasty. J Spinal Disord Tech. 2012;25:10-16.

18. Beaurain J, Bernard P, Dufour T, et al. Intermediate clinical and radiological results of cervical TDR (Mobi-C) with up to 2 years of follow-up. Eur Spine J. 2009;18:841-850. 
19. Lee SE, Chung CK, Jahng TA. Early development and progression of heterotopic ossification in cervical total disc replacement. J Neurosurg Spine. 2012;16:31-36.

20. Bao D, Ma Y, Chen X, Li H, Hu M, Gao T. [Preliminary clinical study on artificial cervical disc replacement by Mobi-C prosthesis]. Zhongguo Xiu Fu Chong Jian Wai Ke Za Zhi. 2011;25(1):70-73. Chinese.

21. Jin DD, Yan HB, Zhang ZM, Li QC, Liu BG. The application of cervical arthroplasty with Mobi-C for treatment of cervical spondylotic radiculopathy. Zhonghua Wai Ke Za Zhi. 2011;49:645-649.

22. Park SB, Kim KJ, Jin YJ, Kim HJ, Jahng TA, Chung CK. X-ray based kinematic analysis of cervical spine according to prosthesis designs: analysis of the Mobi-C, Bryan, PCM, and Prestige LP. J Spinal Disord Tech. Epub November 7, 2013.

23. Oh CH, Kim do Y, Ji GY, et al. Cervical arthroplasty for moderate to severe disc degeneration: clinical and radiological assessments after a minimum follow-up of 18 months - Pfirrmann grade and cervical arthroplasty. Yonsei Med J. 2014;55:1072-1079.

24. Aghayev E, Barlocher C, Sqier F, et al. Five-year results of cervical disc prostheses in the SWISSspine registry. Eur Spine J. 2013;22:1723-1730.

25. Goffin J, Van Calenbergh F, van Loon J, et al. Intermediate follow-up after treatment of degenerative disc disease with the Bryan cervical disc prosthesis: single level and bi-level. Spine. 2003;29:2673-2678.

26. Cheng L, Nie L, Zhang L, Hou Y. Fusion versus Bryan Cervical Disc in two-level cervical disc disease: a prospective, randomised study. Int Orthop. 2009;33:1347-1351.

27. Pimenta L, McAfee PC, Cappuccino A, Cunningham BW, Diaz R, Coutinho E. Superiority of multilevel cervical arthroplasty outcomes versus single-level outcomes: 229 consecutive PCM prostheses. Spine (Phila Pa 1976). 2007;32:1337-1344.

28. Kepler CK, Brodt ED, Dettori JR, Albert TJ. Cervical artificial disc replacement versus fusion in the cervical spine: a systematic review comparing multilevel versus single-level surgery. Evid Based Spine Care J. 2012;3:19-30.

29. Chen J, Wang X, Bai W, Shen X, Yuan W. Prevalence of heterotopic ossification after cervical total disc arthroplasty: a meta-analysis. Eur Spine J. 2012;21:674-680.
30. Wu JC, Huang WC, Tsai HW, et al. Differences between 1- and 2-level cervical arthroplasty: more heterotopic ossification in 2-level disc replacement: clinical article. J Neurosurg Spine. 2012;16:594-600.

31. Bhandari M, Busse JW, Jackowski D, et al. Association between industry funding and statistically significant pro-industry findings in medical and surgical randomized trials. CMAJ. 2004;170:477-480.

32. Schmidt K, Hart AC, editors. DRG Expert: a Comprehensive Reference to the DRG Classification System. 2012 edition. Eden Prairie, MN: Ingenix, 2012.

33. CMS.gov [homepage on the Internet]. Baltimore, MD: Center for Medicare and Medicaid Services (CMS). Available from: http://www. cms.gov. Accessed September 22, 2014.

34. American Medical Association (AMA) Coding Online. American Medical Association [updated January, 2014]. Available from: https:// commerce.ama-assn.org/ocm/index.jsp. Accessed August 1, 2014

35. Nandyala SV, Marquez-Lara A, Fineberg SJ, Singh K. Comparison between cervical total disc replacement and anterior cervical discectomy and fusion of 1 to 2 levels from 2002 to 2009. Spine (Phila Pa 1976). 2014;39:53-57.

36. Qureshi SA, McAnany S, Goz V, Koehler SM, Hecht AC. Cost-effectiveness analysis: comparing single-level cervical disc replacement and single-level anterior cervical discectomy and fusion: clinical article. J Neurosurg Spine. 2013;19:546-554.

37. Qureshi S, Goz V, McAnany S, et al. Health state utility of patients with single-level cervical degenerative disc disease: comparison of anterior cervical discectomy and fusion with cervical disc arthroplasty. J Neurosurg Spine. 2014;20:475-479.

38. Mobi-C® Cervical Disc Prosthesis (two-level) - P110009. U.S. Food and Drug Administration;2014 [updated August 7, 2014]. Available from: http://www.fda.gov/MedicalDevices/ProductsandMedicalProcedures/DeviceApprovalsandClearances/Recently-ApprovedDevices/ ucm367809.htm. Accessed October 31, 2014.
Medical Devices: Evidence and Research

\section{Publish your work in this journal}

Medical Devices: Evidence and Research is an international, peerreviewed, open access journal that focuses on the evidence, technology, research, and expert opinion supporting the use and application of medical devices in the diagnosis, treatment and management of clinical conditions and physiological processes. The identification of novel

\section{Dovepress}

devices and optimal use of existing devices which will lead to improved clinical outcomes and more effective patient management and safety is a key feature. The manuscript management system is completely online and includes a quick and fair peer-review system. Visit http://www. dovepress.com/testimonials.php to read real quotes from authors. 